\title{
Visual and Experiential Knowledge in Observational Cinema
}

\section{Silvio Carta}

\section{(2) OpenEdition \\ 1 Journals}

\section{Electronic version}

URL: http://journals.openedition.org/anthrovision/1480

DOI: 10.4000/anthrovision. 1480

ISSN: 2198-6754

\section{Publisher}

VANEASA - Visual Anthropology Network of European Association of Social Anthropologists

\section{Electronic reference}

Silvio Carta, «Visual and Experiential Knowledge in Observational Cinema », Anthrovision [Online], 3.1 | 2015, Online since 18 October 2015, connection on 10 December 2020. URL : http://

journals.openedition.org/anthrovision/1480; DOI : https://doi.org/10.4000/anthrovision. 1480

This text was automatically generated on 10 December 2020 .

(c) Anthrovision 


\title{
Visual and Experiential Knowledge in Observational Cinema
}

\author{
Silvio Carta
}

\section{Direct contact and unobtrusiveness}

1 Observational filmmaking methods discover and reveal the action of the subjects in the theatres of lived events. One of the hallmarks of unscripted films is a direct contact with experience. The observational approach is generally concerned with informal and intimate conversations, and with rendering visible the inner life of the subjects, including what they may leave unsaid. Observational films strive to achieve closeness in representing the experiences of the subjects, preserving a human scale of encounter between the filmmaker and the subjects to be seen and heard in the finished film. Ongoing events are recorded in the attempt to provide a glimpse of the subjects' lives in their continuity; for this reason, the shooting is tailored to convey their sense of being in the world.

2 At the centre of the observational approach lies a preoccupation with creating a realistic impression of the personalities of flesh-and-blood human beings. It is the very empirical nature of observational films that permits this; in fact, empirical modes of documentary are "predominantly realist with respect to their style and predominantly empirical with respect to their rhetoric" (Henley 2007: 56). This explains the style of observational films, which is resolutely realist, aiming at the preservation of the link with a real time experience. It is a style based on a deliberate attempt at filming the subjects long enough in the complexities of their lives, so that the spectators can follow them in what they do and listen to what they say.

3 In observational films speech, events, and more silent actions, in Marshall's terms, are filmed in order to "try to let the people being filmed express and explain themselves through their own words and actions" (1993: 72). The subjects are neither filmed telling them what to say and how to act nor their "ordinary" experiences recorded by resorting to staging and exegetic commentary. They fill the scene with their own words and natural 
responses, recorded in synch, and their activities give an impression of normality. Most of the time, they continue with what they are doing, without simulating a special performance for the benefit of the camera. They are familiar with the camera, and thus their actions seem to be largely unaffected by its presence. This does not mean that film is a transparent medium and in what follows I will further clarify the nature of film events in relation to the narrative form of observational cinema.

So far I have offered a general discussion of how observational films let situations tell their own story as the subjects go about their lives, striving to come close to their independent life, registering their thoughts and feelings, as well as their way of speaking and moving. Observational filmmakers come close with their camera to the people they are filming. They move the camera around events, recording what the subjects do and how they do it. Their perspective opens an arena of human experience in which actions, thoughts and feelings progress slowly. Thus, observational films provide a channel for the processes of the subjects' lives and their sense of themselves.

\section{Participation, subjectivity, performance}

5 The nature of "truth" created through the techniques of cinematography is frequently a source of misunderstanding. Since this is a relevant question in the understanding of observational films, I shall deal with it now.

6 It is absolutely misleading to assume that observational films advance truth claims that are independent from the personal response of the filmmaker to particular situations. Film testifies to directorial presence. It presupposes a subjective perspective rather than an objective observer with no preconceptions, since the "cameraman is selective in regard to time, focus, angle and framing of each shot" (Hockings 2003: 515). It is undeniable that the personal curiosity of the filmmaker in observational films presupposes criteria of judgment, and that these criteria of judgment may influence the interpretation of events. An invisible observer would lead to the creation of amorphous films. However discreet, or cautious, the vision of the observational filmmaker is organised according to criteria of significance. Shots and angles in observational films are part of an interpretive process of selection. Because of the filmmaker's intentions and authorial implication in the film, ethical problems are never entirely eliminated.

7 What marks out observational films is the creative tension related to the attempt to catch an action (or a series of actions) on the run. Filming in an observational manner means to be close to the subjects and intimately involved with the processes of their lives. Rather than being merely an instrument for recording scientific data in as objective a manner as possible, the camera implicates the filmmaker's subjectivity. This means that the filmmaker "acknowledges his or her entry upon the world of his subjects" (MacDougall 1998: 134). ${ }^{1}$ The perspective of the filmmaker is an acknowledgement of subjectivity in the process of exploring with the camera. Observational films show not only the people who were filmed but also the filmmaker's act of observing (Pink 2006; Nijland 2006b, 2006c).

8 Film produces "truth" by its own methods, a kind of "truth" intrinsic to filmmaking practices which are by no means transparent. All films require a reduction of reality; they do not offer reality itself in the form of transparent, factual materials and this ambiguous distinction between film and reality is clearly at the heart of observational filmmaking. 
The methodologies of observational cinema produce a kind of knowledge based on ongoing practice. Meaning and knowledge can only be achieved through acts of participation. Thus, the "truth" of observational films is, above all else, the result of events in which both the filmmaker and the subjects are involved. The knowledge developed while filming observationally is the product of a collaboration that recreates what Rouch calls the "irreplaceable quality of real contact between the person filming and those being filmed" (2003: 88). The subjects of observational films are "primary producers," since the filmmaker is "greatly dependent on their cooperation and goodwill" (Loizos 1993: 92). The dynamics between filmmaker and subjects during the filmmaking process change the nature of their dialogic understandings. Or, to put it another way, the relationships forged while filming observationally reflect the processual and performative nature of the filmmaking process itself.

The camera in observational cinema is not confined to a passive recording role, but can be seen as an instrument of personal exploration and interrogation of the world. The observational filmmaker is an active user creating a self-conscious form of cinema based on performance. ${ }^{2}$

\section{Rejection of positivism}

10 I have suggested that, to some degree, all filmmaking involves manipulation. The conception of film that informs observational cinema contrasts with the idea of filmmaking as a merely technical process; moreover, it is distant from the naïve positivism that defines observational film in functional terms. According to MacDougall, what is "disappointing in the ideal of filming 'as if the camera were not there' is not that observation in itself is unimportant, but that as a governing approach it remains far less interesting than exploring the situation that actually exists" (1998: 133). ${ }^{3}$ It should be stressed that the concern about veracity and objectivity, especially in the areas of observational and ethnographic filmmaking, are increasingly seen as part of a worn-out nineteenth century topic. To speak of the camera as analogous to scientific instrumentation is to equate the camera to a sort of passive recording device.

11 The idea of the camera as a kind of objective recording device derives from an outmoded positivism. It assumes that the camera can function like the instruments used in the natural sciences - i.e. the microscope or the telescope. ${ }^{4}$ This interpretive framework derives from a concern with scientific knowledge and, more generally, with methodological injunctions about authenticity, anonymity and truthfulness. It "reflects an epistemology that maintains that reality is empirically observable and can be represented with some objectivity and accuracy" (Prins 2010: 283; Loizos 1993: 9).

\section{Camera style, editing and selection}

12 How can we define the camera style of observational films and the way in which they embody certain ideas about the representational status of film? In which sense is the filmmaking apparatus in observational films capable of documenting the manifestations of the real?

Observational filmmaking aims at minimising the impact of film technologies on the film subjects as they go about their lives. It implies a subjective and sensitive engagement on 
the part of the filmmaker in the attempt to "devise ways of bringing the viewer into the social experience of the film subjects" (MacDougall 1998: 134). The filmmaker exploits the virtues of the camera as a tool that reproduces the qualities of the world (e.g. sounds and colours, physical surroundings, speech, body movements) in a form similar to a literal account and, at the same time, as a discreet and subtle catalyst that provokes the responses and conversations of the subjects.

In other words, observational films deploy a camera style that differs from most fiction films in which the observer is not the eye of a human subject behind the camera, as in Hollywood cinema. It is a camera style that does not presuppose an omniscient observer and marks a departure from the fictional style of shooting because it reproduces the perspective of a fallible and prejudiced human being. It is correct to say that observational films recreate the subjective experience of the eye and mind behind the camera through long scenes that reproduce the single point of view of an actual observer. The refusal of fictional editing in observational films is related to the use of long scenes. This is undoubtedly related to the impulse of recording with spontaneity the subjects at the other end of the camera. It is an integral part of the respect for the subjects as individuals, and of the process of highlighting their points of view and beliefs. Unbroken sequence shots edited together with minimal intervention are more suitable when the aim is to preserve the internal time of events in the image-track.

\title{
Risk and chance
}

In his observations about American ethnographic observational filmmaking in the 1960s and 1970s, especially the atmosphere at UCLA and the creation of the Ethnographic Film Programme under Colin Young's tenure, MacDougall writes:

\begin{abstract}
What we wanted to replace was not a narrative view of life, but the worddominated structures of the illustrated lecture film and the all-knowing eye of Hollywood. This resulted in part from our having watched foreign feature films. The people in these films spoke other languages and came from other cultures, but they were still portrayed as individuals. There was no voice on the soundtrack telling you what to think about them. We read their conversations in subtitles and, guided by the filmmaker, we made an analysis of their motivations and actions. Many of these films were also made in unfamiliar ways, in longer takes, avoiding the synthesis typical of the scene construction of Hollywood films'. MacDougall (2001-2002: 88).
\end{abstract}

16 I suggest that we consider two of the fundamental components of observational cinema: chance and improvisation. Observational filmmaking involves the production of unexpected discoveries dependent on circumstance. At one level, it is possible to interpret the residue of chance as the natural expression of the inspired decisions of the filmmaker. At another level, however, chance and uncertainty are intrinsic to films shot at first attempts and with little pre-arrangements. When unexpected accidents take place, it is because observational films are deliberately planned with minimum preparation: almost nothing has been judged or imposed in advance.

More precisely, shooting observationally reflects moment-to-moment judgement in the arena of risk opened by particular situations. This element of risk assigns importance to improvisation and spontaneity, forcing the filmmaker to stay focused on what is going on in front of the camera. Much of the filmmaker's attention is focused on a cinematographic performance that oscillates between the potential and the actual; in 
fact, "interpretation follows filming; major selection takes place during shooting and cutting instead of in scripts written beforehand" (Marshall 1993: 72).

This means that the observational way of shooting is relatively unconstrained, for it is not predetermined by film plans and scenarios dictated by the hierarchy of producers, writers and the various technicians involved in mainstream documentary film productions. Because it requires immediate decision-making, the observational approach to filmmaking is distant from the industrial model of documentary production. ${ }^{5}$ No one would contest that this kind of filmmaking, often practiced by ethnographic filmmakers, departs radically from the many documentaries produced in contemporary media environment dominated by talking heads and a certain kind of journalism that tends to reduce the potential of film to information and textualisations.

\section{Film construction}

19 If one examines the actual processes by which meaning and order are constructed in an observational film, one finds that the cumulative power of the unfolding narrative does not seek to explain in words. Rather, it emerges by means of a web of similarities and contrasts that participate in the creation of a context with chronology. The emergence of a thematic reality coalesces in a naturalistic manner from the different threads that constitute the film. This is especially evident in observational films made by the ethnographic filmmaker, who "typically seeks to convince the spectator of the validity of his or her understanding of the subjects' world by re-presenting evidences of that world in a naturalistic manner" (Henley 2007: 56).

The structure of observational films gives coherence to different fragments of experience, letting a later sequence explain an earlier one through a process of ordering and selection. This way of making an argument without textual explanation relies on the possibilities of visual revelation. It relies on an "element of simultaneity, which reflects the intersubjectivity of the participants" (MacDougall 2006: 50). The viewer finds meaning in the realities of the subjects, captured eloquently on film without verbal instructions. Interpretations and comparisons are drawn from a series of discreet events held together by the flow of a chronological narrative. This attempt to eliminate the distance between spectators and subjects is one of the fundamental precepts of films based on first-hand observation.

21 Clearly there is a link between the cinematic discourse of revelation in observational films and the way they address the spectator. Observational films might let viewers judge the evidence presented in the form of an editing structure without a soundtrack telling them how to interpret it - what to think about it. The viewers are expected to fill the unmediated space of the film with their own understandings and judgements, as it often happens in everyday life. As Vaughan puts it, there is "no sharp demarcation between misunderstandings of documentary and the misunderstandings of life" (1999: 78). In observational films, like in ordinary life, we draw our own conclusions and we are left to judge from what we see and hear.

22 This is why it is a serious misconception to assume that films that lack commentary which is, after all, only one kind of soundtrack - cannot provoke fertile discussions, not least because such films seem to allow the audience to grant the visuals further thought. This is not always possible in films driven by voice-over commentary, which is often ill- 
delivered because it talks down to viewers, keeping them from developing their own thoughts about what they see in the film. Voice-over commentary acts as a means of telling the viewers what they are seeing, not as a way of presenting the subjects' struggles with the contradictions of daily life.

Instead of providing verbal information that merely contextualizes visual obscurities and abstract meanings related to the filmed events, verbal scripts tend to assume an omniscient narrative stance that imposes very strict limitations to the viewers' ability to learn from the thoughts and actions of people in documentary films.

\section{"Showing" and "telling"}

one hand, and Russell's distinction between knowledge by acquaintance and knowledge by description - a distinction that should be considered as indicative rather than definitive. Whereas telling permits knowledge at a distance, that is, abstractly coded knowledge acquired from the generality of language, showing allows us to insert ourselves experientially into "the environment of a way of acting" (to borrow Wittgenstein's terms) by a form of acquaintance. The knowledge by acquaintance that we grasp in observational films is not derived from a description acquired from language. Because it derives from the experiential qualities of an environment, it is less influenced by what we already know. to the visualisation of an action (i.e. the nuances of movement and colour in a facial expression) than to the verbalization of the same action. In fact, an action captured by the camera and that same action described through voice-over commentary exist on two different plains: images and expository information do not share the same responsibilities (Hockings 2003: 515). An understanding of the controversy between telling and showing is beneficial in the context of this discussion. On the one hand, a film that "tells" is a film that promotes the didactic oral pronouncements of a narrator. It provides guidance concerning what the viewers should think and what conclusions they should draw. It is easy to point to the didactic functions of the disembodied word in these films. Their tendency is to voice the authority and ideological agenda of an oral commentary. Because voice-over commentary is often uniquely informative, it tends to reduce meaning to a sign without advancing our understanding of the image-track. This does not mean that an extradiegetic commentary always restricts the world pictured on the screen; however, it is true that it does not put the audience into a life experience, for it does not penetrate deeply into the visible world. In effect, voice-over exegesis often produces a filmed essay that directs the viewer's attention towards the cohesion of the world of discourse at the expense of the visual layer (Kracauer 1960: 104). ${ }^{6}$

On the other hand, an observational film is a film that "shows": it explores events and visual phenomena by making the audience cooperative. It concerns itself with the fluidity and ambiguity of actions presented without commentary. This lack of overt mediation allows the spectators to think and draw their own conclusions and interpretations. The 
viewers are assumed to have direct access to the visual and embodied experience of the subjects. This does not mean that "showing" cannot be a covert form of authorial manipulation and intrusion (Doane 1980: 46); the avoidance of voice-over narration does not guarantee objectivity, for showing is neither untainted and unadulterated nor intrinsically egalitarian. Rather, it means that "telling" is similar to the superimposition of an oral mode of narration on another kind of narration that is not immune from moral and political criticism. In fact, "all filmmaking is a form of discourse fabricating its effects, impressions, and point of view" (Nichols 1983: 18). It is clear then that "only showing" is by no means transparent, and yet this type of narration allows the viewers a closer relation to the significance of images.

\section{Words and Images}

28 Observational films draw the attention of the critic to the disparities between images and words. That words and images occupy quite different domains will not be disputed. Images enable us to learn from what we see; however, there are serious limitations in the information conveyed through visual images. Certain topics are covered more adequately in writing. Statistical and numerical abstractions are difficult to convey visually. Most of the time, the "camera can only record events that happen, and only behaviour it is allowed to see" (Marshall 1993: 73).

The disparities between images and words are perhaps most evident in the phenomenon known as double-telling, which usually refers to instances of overlapping of images and narration. When the narration corresponds closely to the picture track there is a danger of double perspective, a sense of twice-told things. This duplication works against simplicity, for it presents a vision of what the narration already states. Ethnographic and documentary filmmakers are familiar with this sense of redundancy, and try to avoid the double-telling effect. However, even if verbal narration may redouble the mood of the images, this does not mean that voice-over information can "double-tell" to all the visual aspects onscreen.

It can be said that that there are significant expressive relationships between verbal expression and image, but also that the functions of words and images, understood as different sign systems, are always in tension. It is important to emphasise that words are arbitrary signs that add a certain slant to filmic images. Voice-over narration can be used to distort the "meaning" of images or alter a documentary's tone and content; according to Barthes, words "anchor" the meaning possible within the image. The interpretation of free signifiers in the image can be oppressed or, rather, repressed by the ideological meanings of the verbal text. The linguistic text that captions a picture, for example, can resolve the ambiguities placed within the image. This is the anchorage, the caption that "anchors" the viewer's interpretation of a picture, which helps to "choose the correct level of perception" (Barthes 1977: 38-41). ${ }^{7}$

31 By overseeing the images, words often do not provide an argument based on the kind of inductive reasoning made possible in observational films. In effect, the information remains inaccessible to the images. A kind of chastisement of the image by the word underscores the autonomy of visual experience, which is not, however clouded by speech, a manifestation of logos. The idea that images should be mastered by words is referred to as "iconophobia"; indeed, the iconophobes are those who believe that images should be subservient to words (Mitchell 1986). 

Loizos' expression, they tend to get "away from ex cathedra explanations and rely instead upon the self-revelation and social interactions of the people portrayed" (1993: 93). This approach redresses the traditional hierarchy of image and voice-over that characterises exegetic documentaries. However, the break with the conventions of exegetic voice-over does not mean the marginalisation of the verbal. It does not mean the privileging of the non-verbal over language. On the contrary, it means that observational films include language without being entirely defined by it. The contextualisation of language and its reinsertion in the matrix of cultural life gives a new emphasis to the verbal. This is possible only when the filmmaker follows closely the processes of the subjects' lives. These include informal conversations and the routines of the everyday, so that the final film effectively becomes a process, a "conceptual space within a triangle formed by the subject, film-maker, and audience and represents an encounter of all three" (MacDougall 1998: 193) ${ }^{8}$

\section{Excess in visual narrative}

Images in observational films challenge the power of voice-over commentary. In film what "becomes vivid is the excess that remains after evidence and argument, rhetoric and conviction have had their say" (Nichols 1991: 234). Indeed, many of the elements of the image are unreliable and unaccountable. They can be defined as the "excess" in visual narratives. A number of tactile and physical elements, for example, depend exclusively on the materiality of film. As such, they "do not participate in the creation of narrative or symbolic meaning" (Thompson 1986: 131). These elements distract the viewers at the level of non-narrative structure. Building on this, I suggest that the opaqueness of images resists the level of containment established by words: visual appearances remain only unsatisfactorily explained.

An acknowledgment of the anti-narrative frame of reference produced by film images is fundamental in understanding their subversive powers, as well as the ways in which their relation to the real exceeds representation: "whatever else we may say about the constructed, mediated, semiotic nature of the world in which we live, we must also say it exceeds all representations" (Nichols 1991: 110; Heath 1986: 130-1). The visible signifiers in observational films, being contradictory or even unexplained, affect viewing experience but they also resist appropriation, showing the limitations of explanatory and descriptive orders narration. This kind of "excess" is defined by Barthes as figuration; film "will always be figurative (which is why films are still worth making) - even if it represents nothing" (1975: 56; quoted in MacDougall 1998: 73).

In other words, the nature of images is potentially chaotic and spontaneous. Indeed, "all images are polysemous; they imply, underlying their signifiers, a 'floating chain' of signifieds" (Barthes 1977: 39). This inarticulacy of the image in visual narratives is at the same time a disadvantage and a sign of unique power. It has to do with the ambiguity that troubles the critic of cinematic narratives. The same image, for instance, can be used at the same time to show a visual object and to represent an idea. "Excess" and the difficulties of separating the actual from the ideal are related to the "particularly powerful and troubling role of the image in cinematic narrative" (Mermin 1997: 41). The same image presents literal aspects of objects but it also carries more symbolic and connotative meanings. It can serve many purposes. 


\section{Thick descriptions and experiential knowledge}

Today observational films for anthropology are imbricated in the professional career structures of anthropologists who make them and the programmes that teach this method of ethnographic filmmaking. Historically, however, observational films have exhibited a tendency to bypass professional identities; a number of observational films explore important anthropological ideas without being formally anthropological and without engaging explicitly with theoretical debates in the academic field of anthropology. This confirms "undisciplined" status of ethnographic film as a genre within the academic world of anthropology. That the filmmaker must be knowledgeable about anthropology does not seem a definitional criterion of ethnographic film. This does not exclude that the "participation of the anthropologist at one or several levels of production" is an "important criterion making for the automatic inclusion of the film in ethnographic category" (Balicki 1988: 33; Heider 1976).

The category of ethnographic film is intuitively based on a cross-cultural perspective. Observational films echo recent anthropological interest in the visual contexts in which "culture" is embodied. The resonances and the evocations of cultural life in observational films are recorded in the form of actual events that restore "culture" to its material world and phenomenological background. ${ }^{9}$ As Grimshaw and Ravetz suggest, one of anthropology's foundational tenets is the sensory and experiential immersion in another way of life; indeed, the anthropological enterprise reflects a subjective experience based on observation and participation. In this sense, observational cinema is a form of contemporary art, a special kind of ethnographic endeavour linked to a commitment to experiential epistemologies rather than to cross-cultural perspective. What defines ethnographic filmmaking practices is not only an engagement with the dialectics of an encounter between cultures, but also a deep focus on the empirical. This means that observational films can be ethnographic because of their commitment to experience.

Observational films do not guide the viewer; rather, they show events from within, without dubbing. This way of showing removes a sense of distance from the observer, whose experience is close to the understandings emerging in the interaction between social actors during fieldwork research. It provides access to a kind of experience similar to that of anthropologists immersed in a research setting.

The activities of observational filmmakers are close to those of socio-cultural anthropologists involved in the initial process of data selection. Observational ethnographic films provide important evidence of the mutual understandings and relationships that usually emerge in the process of developing anthropological knowledge before it becomes written in a monograph. Crawford observes that both "ethnographic filmmakers and anthropologists are engaged and governed by the communicative conditions of human intersubjectivity" (1992: 68). The crucial point here is that anthropologists seek to draw meaning from real life situations through ethnographic techniques and ways of working which are similar to those adopted by observational ethnographic filmmakers. Like ethnographic filmmakers, "ethnographers always define reality at the moment they discover it" (Hastrup 1992: 10). The principles governing their respective praxes are very similar. As Marshall writes, the techniques of observational cinema require filmmakers to know the people in their films. Since shots are not selected by written scripts, stories unfold in the words and actions of the subjects; 
it is necessary for the filmmakers to follow the events. Time is required for stories to develop. (...) you spend as long as you can with the people you are filming (1993: 73).

Ethnographic filmmakers and anthropologists, albeit with different results, are engaged in an open interaction and in the provocation of their subjects into revealing their experiences, interpretations and relations with material culture.

The authority of anthropologists is rooted in the experience of having "being there" (Clifford 1988: 22; Geertz 1988: 4-5). The main difference between anthropologists and ethnographic filmmakers is that the latter develop anthropological interpretations grounded in film through acts of recording what is going on in front of the camera.

The observational potential of a filmic way of working lies in its ability to capture what is happening in a detailed manner. Its relevance for anthropology as it is practiced today consists in its power to recreate the context and experience of fieldwork in which ethnographers conduct their research. As MacDougall points out:

films, despite their fragmentation, are permeated with the imprint of human environments. Each social landscape is a distinctive sensory complex, constructed not only of material things but also of human activities and the bodies of human beings themselves' (2006: 58).

As research method, observational ethnographic films make "field enquiries more accessible and 'thicker' in Geertz's sense" (Loizos 1992: 60). For this reason, it can be said that observational films provide fine-grained visual accounts that correspond to the "thick descriptions" of postmodern ethnography. According to Hockings, film is a "means - a very good means - of recording and preserving observations of events" (2003: 514).

This is because the observational filmmaker films the complexity of what the subjects do and say with fidelity to the empirical conditions governing their performances. Observational films exploits the "co-presentation of objects and sensory patterns that writing tends to present in a more selective and linear fashion" (MacDougall 2006: 43). A great deal of actions, gestures, and the complexities of the subjects' lives are meticulously observed and filmed comprehensively from within; in effect, descriptive sequences with synchronous sound reveal much about the rhythms of actual life. The shots "constantly drift toward the actual complexity and indeterminacy of the experienced world" (MacDougall 2006: 41).

45 Thus the clearest link between observational ethnographic films and contemporary anthropology is that the content of thick films moves away from the requirements of a script by valorising the texture of the direct experience captured in the rushes. As Marshall observes, "events are elaborated in thick films. Supporting characters are given a suggestion of independent life" (1993: 108). Extended observational sequences, like thick literature, foreground what are usually background materials and, it must be added, present events in their complexity and multidimensionality. They open an arena of ethnographic description that conveys a wealth of information and nuances about slices of life intimately recorded.

\section{Observational cinema and postmodern anthropology}

Unlike a script written beforehand, lengthy shots of ongoing pieces of behaviour found in observational films are open to the evidential and experiential resonances of situations before they become categorised in more abstract concepts. Their thickness suggests that experience is knowledge, and vice versa. Filming the same subjects in different situations 
renders their insights and feelings before they are expressed in opinions conveyed through language. It provides exhaustive and comprehensive descriptions of roundly developed individuals with complex lives. ${ }^{10}$

As an experimental form of anthropological inquiry, observational cinema reproduces contents which are indeterminate and likely to slip through the net of scholarly language and expository prose. As such, they cannot be reduced or controlled as messages and explanations. Thus, the description of particular socio-cultural systems through the film provides fine grain-accounts that resist the impulse to shape reality by means of discursive choices.

To a large extent, this depends on the experiential status of observational films. They represent a way of exploring new territory in the production of experiential knowledge. Because of their representational status, observational films can be classed as an interesting alternative to the knowledge produced through written monographs. To the extent that film-based research, directly or indirectly, displays other modes of understanding that do not conform to usual ways of conceiving anthropological knowledge, the specific modes of expression of film question the reproduction of academic canons. This questioning of academic boundaries within ethno-anthropological disciplines, in turn, is to a large extent the product of the experimental nature of film as a way of knowing.

It could be said with total justification that the uses of sound and images in observational films open up new areas of ethnographic understanding through the disruption of conventional anthropological perspectives. As such, they are a form of postmodern anthropology. As Grimshaw writes:

Any attempt to understand observational cinema benefits from a change in the dominant theoretical paradigms governing both anthropology and film studies. Renewed interest in phenomenological approaches, the emergence of sensory perspectives, and a reconsideration of the question of mimesis has greatly enriched the intellectual context in which to locate any new appreciation of observational cinema (2002: 82).

Through its emphasis upon accidents and imperfections, the experiential domain offered in observational films represents an inherently new form of anthropology. This experimental anthropological form combines the aural and visual qualities of film with cinematic ways of exploring various cultural and social interests, going beyond the conception of film as a visual supplement to textual works. As a radically different form of anthropological practice, observational cinema provides excursions into the specific location in which films have been shot. These excursions include nonverbal "ways of knowing", everyday and banal aspects of meaning, and unforeseeable moments of revelation. More radically, observational films render the soundscapes of the world in which the subjects live. Because film practices accommodate indeterminacy and excess more than words, audiovisual artefacts expand the arena of anthropology in instructive ways that often tend to be overlooked.

51 A demonstration of this is that anthropological film artefacts, like motion pictures in general, present life-like elements in an experiential fashion that emphasises the emotional life of the subjects. The direct representation of sensory and experiential qualities in observational films stimulates our thoughts and generates empathy for what is going on before the camera. This empathetic involvement, relying on multiple perceptual modes, is both cognitive and emotional. It also plays a part in dissolving 
traditional dichotomies between body and mind, emotional and intellectual. The combination of rapport and compassion with the subjects touches the spectator at the level of feelings, but it also engenders a deeper form of experience. This has to do with the fact that in providing an alternative, empathetic "way of knowing", the observational camera also recreates a sense of corporeal involvement in the world: skin, gestures, physical characteristics and body language in general are reproduced with fidelity. MacDougall once again comments on this:

In viewing a film, we respond in various ways to the bodies of the people we see on the screen, but we also respond to the filmmaker's body as we experience it through the decisions that guide the movements of the camera, how it frames events, and in matters of proximity and positioning in relation to the subjects (2006: 54).

Thus, one could make a case that viewers engage with observational films with all their senses. Observational filmmaking is an embodied and constructed practice involving an awareness of movement and posture, as well as the more visceral aspects of bodily experience. This does not mean that images in observational films do not have their limitations. Rather, it means that many qualities that are perceived as images' shortcomings are also part of their strength.

\section{Conclusion}

This article offered a discussion of the techniques of observational filmmaking and their exploratory function, examining this filmmaking style with respect to the filmmaking process, the role of subjectivity and the interaction of words and images. In doing this, it invoked the old opposition between words and images, namely between the transfer of meaning through words, language and texts on the one hand, and the experiential forms of knowledge produced through images, film and video on the other. Words and language, with their clear-cut, abstract but also limiting concepts can only create a discourse in a consecutive, linear sequence. Images - and film images in particular - offer information in an opener, more dynamic and less imperative way, and mostly even simultaneously. ${ }^{11}$ Some uses of voice-over commentary may limit the potential of images, scale it down by the "chastity belt" of language, reducing the chances for the spectator to have a new experience. The article therefore tends towards a humanist approach seeking revelation rather than illustration; such a approach would lead to new cultural insights and thus make a refreshing contribution to innovating anthropology.

\section{BIBLIOGRAPHY}

Balicki, Asen. 1988 Anthropologists and Ethnographic Filmmaking. In Anthropological Filmmaking, ed. J. R. Rollwagen, 31-46. New York: Harwood Academic Publishers.

Barker, J.M. 1995. Bodily Irruptions: The Corporeal Assault of Ethnographic Narration. Cinema Journal 34: 3, 57-76. 
Barthes, R. 1975. The Pleasure of the Text, trans. S. Heath. Glasgow: Fontana/Collins.

Barthes, R. 1977. The Rhetoric of the Image. In Image/Music/Text, ed. S. Heath, 32-51. New York: Hill and Wang.

Clifford, James. 1988. The Predicament of Culture: Twentieth-Century Ethnography, Literature and Art. London: Harvard University Press.

Crawford P.I. 1992. Film as Discourse: The Invention of Anthropological Realities. In Film as Ethnography, eds P. I. Crawford and D. Turton, 66-82. Manchester: Manchester University Press.

Doane, M. A. 1980. The Voice in the Cinema: The Articulation of Body and Space. Cinema/Sound, Yale French Studies 60, 33-50.

Geertz, Clifford. 1988. Works and Lives. Stanford: Stanford University Press.

Goldschmidt, W. 1972. Ethnographic Film: Definition and Exegesis. PIEF Newsletter 3:2, 1-3.

Grimshaw, Anna and Amanda Ravetz. 2005. Visualizing Anthropology. Bristol: Intellect.

Hastrup, K. 1992. Anthropological Visions: Some Notes on Visual and Textual Authority. In Film as Ethnography, eds. P.I. Crawford and D. Turton, 8-25. Manchester: Manchester University Press.

Heath, S. 1986. Film and System: Terms of Analysis. In Narrative, Apparatus, Ideology ed. P. Rosen. New York: Columbia University Press.

Heider, K. G. 1976. Ethnographic Film. Austin: University of Texas Press.

Henley, Paul. 2007. Seeing, Hearing, Feeling: Sound and Despotism of the Eye in "Visual" Anthropology. Visual Anthropology Review 23: 1, 54-63.

Hockings, Paul. 2003. Conclusion: Ethnographic Filming and Anthropological Theory. In Principles of Visual Anthropology, ed. P. Hockings, 507-529. New York: Mouton de Gruyter.

Kracauer S. 1960. Theory of Film: The Redemption of Physical Reality. London: Oxford University Press.

Loizos, Peter. 1992. Admissible Evidence? Film in Anthropology. In Film as Ethnography, eds P. I. Crawford and D. Turton, 50-65. Manchester: Manchester University Press.

Loizos, Peter 1993. Innovation in Ethnographic Film: From Innocence to Self-consciousness 1955-1985. Manchester: Manchester University Press.

MacDougall, David. 1994. Whose Story Is It? In Visualizing Theory: Selected Essays from V.A.R., ed. L. Taylor, 27-36. New York and London: Routledge.

MacDougall, David 1995. Subtitling Ethnographic Films: Archetypes into Individualities. Visual Anthropology Review 11: 1, 83-91.

MacDougall, David 1998. Transcultural Cinema. In Transcultural Cinema, intro. by L. Taylor, 245-278. Princeton: Princeton University Press.

MacDougall, David 2001-2002. Colin Young, Ethnographic Film and the Film Culture of the 1960s. Visual Anthropology Review 17(2): 81-88.

MacDougall, David 2006. The Corporeal Image: Film, Ethnography and the Senses. Princeton; Oxford: Princeton University Press.

Marshall, J. 1993. Filming and Learning. In The Cinema of John Marshall, ed. J. Ruby, 1-134. Philadelphia; Reading: Harwood Academic Publishers. 
Mermin, E. 1997. Being Where? Experiencing Narratives of Ethnographic Film. Visual Anthropology Review 13: 1, 40-51.

Metz, C. 1974. Film Language, trans. M. Taylor. New York: Oxford University Press.

Mitchell, W.J.T. 1986. Iconology: Image, Text, Ideology, Chicago: University of Chicago Press.

Nichols, B. 1991. Representing Reality. Bloomington: Indiana University Press.

Nijland, Dirk J. 2006a. Film and Non-verbal Expressions of Culture Amongst the Tobelo. In Reflecting Visual Ethnography: Using the Camera in Anthropological Research, eds M. Postma and P. I. Crawford, 52-77. Leiden/Højbjerg: CNWS Publications/Intervention Press.

Nijland, Dirk J. 2006b. Ritual Performance and Visual Representation: The Body, the Brain and Video Supported Observation. In Reflecting Visual Ethnography: Using the Camera in Anthropological Research, eds M. Postma and P. I. Crawford, 26-49. Leiden/Højbjerg: CNWS Publications/ Intervention Press.

Nijland, Dirk J. 2006c. The Bilan Adventure: The Shadow-journey. In Comité du Film Ethnographique, Festival International du Cinema Ethnographique Jean Rouch, http:// comitedufilmethnographique.com/dirk-nijland/.

Pink, S. 2006. The Future of Visual Anthropology: Engaging the Senses. London and New York: Routledge.

Prins, H.E.L. 2010. Visual or Virtual Anthropology? In the Wilderness of a Troubled Genre. Reviews in Anthropology 26: 4. 279-294.

Rouch, Jean 2003 [1975]. The Camera and Man. In Principles of Visual Anthropology, 79-98. New York: Mouton de Gruyter.

Rouch, Jean 1979 [1971]. On the Vicissitudes of the Self: The Possessed Dancer, the Magician, the Sorcerer, the Filmmaker, and the Ethnographer. Studies in Visual Communication 5(3): 2-8. English translation of: Essai sur les avatars de la personne: du possédé, du magicien, du sorcier, de ciné et de l'ethnographe. In La Notion de personne en Afrique noire, 528-544. Colloques internationaux du CNRS 544, Paris, 1971.

Russell, B. 1912. The Problems of Philosophy. London: Oxford University Press.

Sobchack, V. 1992. The Address of the Eye: A Phenomenology of Film Experience. Princeton: Princeton University Press.

Thompson, C. 1986. The Concept of Cinematic Excess. In Narrative, Apparatus, Ideology, ed. P. Rosen. New York: Columbia University Press.

Vaughan, Dai. 1999. The Aesthetics of Ambiguity. In For Documentary: Twelve Essays, 54-83. Berkeley: University of California Press.

Young, Colin. 2003 [1975]. Observational Cinema. In Principles of Visual Anthropology, ed. P. Hockings, 99-113. The Hague: Mouton.

\section{NOTES}

1. MacDougall writes: "No ethnographic film is merely a record of another society; it is always a record of the meeting between a filmmaker and that society" (1998: 134). The observer in ethnographic films is not a "machine, much less a god, but an eye and mind behind the camera" (MacDougall 2001-2002: 88). 
2. The theoretical discussion of ethnographic films made in the observational style should be considered with reference to the production of Rouch's cinema and what he called anthropologie partagée (Rouch 1979), namely films shot in the first person singular, with long takes and a moving camera, significantly named plan-séquence.

3. Furthermore, for the "filmmaker to evince no interests, no distinctive way of seeing things, to pretend to anonymity" is disingenuous, for the filmmaker is "already subjectively and physically implicated in the fabric of a film" (MacDougall 2001-2002: 87). MacDougall observes that the "impossibility of maintaining anonymity in films may be one reason why a focus on individuals has been more common in ethnographic films than in ethnographic writing" (2006: 55).

4. An example of this can be found in the positivist notion that defines ethnographic film as that "which endeavours to interpret the behaviour of people of one culture to persons of another culture by using shots of people doing precisely what they would have been doing if the camera were not there" (Goldshmidt 1972: 1). According to this definition, the aim of this kind of "scientific" ethnographic film is to "mimetically record reality as it exists before the neutrally observing camera" (Prins 2010: 283).

5. This does not mean that observational cinema is without constraints or ungoverned by a different network and hierarchy of associations going on between filmmaker, subjects and the academy. Observational films belong to the tradition of documentary and ethnographic cinema that "required a form of immediate decision-making which could not be achieved within the industrial model of documentary production, where films are scripted and responsibilities are divided among the director, camera operator, and other technicians. Nor could it result effectively from collaborations between filmmakers and anthropologists. The anthropologist had to be the filmmaker, or vice versa" (MacDougall 2001-2002: 83).

6. This does not mean that voice-over cannot produce fracture, nuance and dislocation, as there is more than a single use of voice-over narration. An ironic instance of the theoretical distaste of anti-telling theorists is Metz's reaction to the soundtrack, which he compares to the "chattering wife" who must be invited reluctantly to her husband's professional dinners (Metz 1974: 74).

7. However, we may add that whereas it is true that images are connoted by words in powerful ways, it is also possible that words can lose their innocence or ambiguity when placed close to images. Barthes also individuates a mechanism, which he christens "relay" that exceeds the image in film. In this case the verbal text "does advance the action by setting out, in sequences of messages, meanings that are not to be found in the image itself" (Barthes 1977: 38-41).

8. In this light, MacDougall suggests that ethnographic films should be assessed as "sites of meaning potential" that can be read at a variety of different levels and in a variety of different contexts (1998: 77).

9. Observational films provide an exploration of what MacDougall defines as "social aesthetics" or "culturally patterned sensory experience" (1995: 5). He writes that the "aesthetic dimension of social experience remains a relatively undeveloped area in the human sciences. It is an area particularly open to investigation in the visual media. One can see that many ethnographic filmmakers, while they outwardly pursue conventional anthropological agendas, are already temperamentally and intuitively more attuned to this possibility" (2006: 59).

10. Indeed, MacDougall writes that it is in the "realm of interpersonal relations that the visual complexity of the image has particular relevance for social research, as it does for cinema as an art. The possibility of grasping a complex social event simultaneously through its various dimensions of gesture, facial expression, speech, body movement, and physical surroundings is something that a text can approach only with great difficulty" (2006: 50).

11. Film images do not only represent one or more phenomena but also some of their broader context. In the 1970s and 1980s, Adrian Gerbrands and Bruce Kapferer contrasted the communicative multi-dimensional character of the image with the one-dimensional character of language (Nijland 2006a: 71). 


\section{ABSTRACTS}

This article examines observational filmmaking methods, which have been influential in shaping ethnographic cinema. It offers a theoretical discussion of the techniques of observational filmmaking and their exploratory function, providing an analysis of the general features of observational films. The paper examines observational cinema with respect to the degree of control exerted over the filmmaking process, camera style and editing, the role of subjectivity and the interaction of words and images. The article concludes with an analysis of the contribution of observational cinema in the creation of corporeal and experiential forms of knowledge foregrounded in postmodern anthropology.

Cet article examine les méthodes du cinéma d'observation qui ont joué un rôle fondamental pour le cinéma ethnographique. Un débat théorique sur les techniques du cinéma d'observation et leur fonction exploratoire permet une analyse des principales caractéristiques des films d'observation. Puis on évalue le cinéma d'observation en fonction du degré de contrôle exercé lors du tournage, avec le style de la caméra et du montage, la place de la subjectivité et l'interaction entre les mots et les images. L'article se termine par l'analyse de la contribution du cinéma d'observation à la création de formes corporelles et empiriques du savoir privilégiées dans le courant anthropologique postmoderne.

En este artículo se examinan los métodos cinematográficos observacionales, que han influido en la forma del cine etnográfico. Se ofrece un debate teórico de las técnicas del cine observacional y su función exploratoria y se proporciona un análisis de las características generales de las películas observacionales. En el artículo se examina el cine observacional con respecto al grado de control ejercido sobre el proceso cinematográfico, el estilo de la cámara y la edición, el papel de la subjetividad y la interacción de palabras e imágenes. El artículo concluye con un análisis de la contribución del cine observacional a la creación de formas corpóreas y experienciales de conocimiento que destaca en la antropología moderna.)

\section{INDEX}

Mots-clés: anthropologie visuelle, film ethnographique, cinéma vérité, film documentaire, connaissance expérimentale

Keywords: visual anthropology, ethnographic film, observational cinema, documentary film, experiential knowledge

Palabras claves: antropología visual, cine etnográfico, cine observacional, cine documental, conocimiento experiencial

\section{AUTHOR}

\section{SILVIO CARTA}

SXC741@bham.ac.uk 
Silvio Carta completed his PhD in Italian Studies at the University of Birmingham. 